\title{
Two Homogeneous Servers Limited Capacity Markovian Queueing System Subjected to Varying Catastrophic Intensity
}

\author{
N. K. Jain \\ Professor,Department of Statistics \& O. R \\ Kurukshetra University Kurukshetra \\ Haryana - INDIA
}

\author{
Gulab Singh Bura \\ Assistant Professor \\ Department oD\&pdistriosn\& of.SPatistics \& O. R \\ Kurukshetra University Kurukshetra \\ Haryana - INDIA
}

\begin{abstract}
In the present paper, we analyze the effect of varying catastrophic intensity on a limited capacity Markovian queueing system with two identical servers. The time dependent probabilities for the number in the system are obtained. The steady state probabilities and various measures of performance are also provided. Further some important particulars cases are also derived and discussed.
\end{abstract}

\section{Keywords}

Two homogeneous servers, varying catastrophic intensity, Laplace transforms, Markovian queueing system.

\section{INTRODUCTION}

During the last three decades, the concept of catastrophes is based on the assumption that with the occurrence of catastrophe, all the customers in the system are destroyed instantly and simultaneously, the system becomes ready to accept new customers. A large number of research papers have appeared on queues incorporating the effect of catastrophes. These have a wide range of applications in computer communication see e.g. Chao (1995), Kumar and Arivudainambi (2000), Jain and Kumar (2005a, b, c; 2006), and in Biological sciences [Crescenzo et al. (2003), and Jain and Kanethia (2006)], and in population processes [see. e.g., Brockwell et al., (1982) and Bartoszynski et al., (1989)]. In the above mentioned work, all the researchers' have used the assumption that with the occurrence of catastrophe, all the customers in the system are destroyed. But it is not always the case. In many practical situations this assumption does not hold good. So necessary amendment is incorporated in the paper of Jain and Bura (2010) in the form of varying catastrophic intensity to destroy a finite number of customers at a time. When the system is not empty, the catastrophes occur according to a Poisson Process with rate $\xi$ with intensity $\mathrm{C}_{\mathrm{r}}$. It depends upon the intensity of the catastrophe whether it destroys all the customers or not. If it destroys all the customers, immediately then the system becomes ready to accept the new customers. The catastrophic intensity may follow any distribution. The concept of varying catastrophic intensity has numerous applications in a wide variety of areas particularly in agriculture and biosciences etc. In paper (2010), we studied a Markovian queueing model with single server subjected to varying catastrophic intensity. In real life it is not necessary that a queueing system should have only one server. Practically they may have more than one server. A similar study was made by Kumar and
Madheswari (2002) with (degenerated) catastrophe i.e. the occurrence of a catastrophe destroys all the customers in the system immediately without affecting the functioning of the system otherwise. Varying intensity catastrophe does not destroy all the customers but a finite number $(\leq N)$. The introduction of the varying intensity catastrophe makes the system more complicated and generalized. We in this paper confine ourselves to a Markovian queue with two identical servers subjected to varying catastrophic intensity. The time dependent solution and the steady state solution have been obtained explicitly recursively. Some important measures of performance and particular cases have also been derived and discussed.

\section{QUEUEING MODEL}

The queueing model investigated in this paper is based on the following assumptions:-

(1) The customers arrive in the system one by one in accordance with a Poisson process in a single queue with rate $\lambda>0$.

(ii) There are two identical servers. The service times of the customers are independently identically exponentially distributed with rate $\mu>0$.

(iii) When the system is not empty, catastrophes occur according to a Poisson process with rate $\xi$ and intensity $\mathrm{C}_{\mathrm{r}},(\mathrm{r}=1,2,3, \ldots, \mathrm{N}), \sum_{\mathrm{r}=1}^{\mathrm{N}} \mathrm{C}_{\mathrm{r}}=1$ It depends upon the intensity of the catastrophe that how many customers are destroyed instantaneously.

(v) The queue discipline is first- come- first- served.

(vi) The capacity of the system is limited to N. i.e., if at any instant there are $\mathrm{N}$ customers in the system, then the customers arriving in the duration for which the system remains in state $\mathrm{N}$ are not permitted to join the queue and considered lost for the system with probability one.

(vi) Initially, there are zero customers in the system. Define

$\mathrm{P}_{\mathrm{n}}(\mathrm{t})=$ the probability that there are $\mathrm{n}$ customers in the system at time t. 


\section{TRANSIENT SOLUTIUON}

The differential- difference equations governing the system are:

$\mathrm{P}_{0}^{\prime}(\mathrm{t})=-\lambda \mathrm{P}_{0}(\mathrm{t})+\mu \mathrm{P}_{1}(\mathrm{t})+\xi \sum_{\mathrm{n}=1}^{\mathrm{N}} \sum_{\mathrm{r}=\mathrm{n}}^{\mathrm{N}} \mathrm{c}_{\mathrm{r}} \mathrm{P}_{\mathrm{n}}(\mathrm{t})$

$\mathrm{P}_{1}^{\prime}(\mathrm{t})=-(\lambda+\mu+\xi) \mathrm{P}_{1}(\mathrm{t})+\lambda \mathrm{P}_{0}(\mathrm{t})+2 \mu \mathrm{P}_{2}(\mathrm{t})+$

$+\xi \sum_{\mathrm{r}=1}^{\mathrm{N}-1} \mathrm{c}_{\mathrm{r}} \mathrm{P}_{(1+\mathrm{r})}(\mathrm{t})$

$\mathrm{P}_{\mathrm{n}}^{\prime}(\mathrm{t})=-(\lambda+2 \mu+\xi) \mathrm{P}_{\mathrm{n}}(\mathrm{t})+\lambda \mathrm{P}_{(\mathrm{n}-1)}(\mathrm{t})+2 \mu \mathrm{P}_{(\mathrm{n}+1)}(\mathrm{t})+$

$\xi \sum_{r=1}^{N-n} c_{r} P_{(n+r)}(t), n=2,3, \ldots . ., N-1$

$$
\mathrm{P}_{\mathrm{N}}^{\prime}(\mathrm{t})=-(2 \mu+\xi) \mathrm{P}_{\mathrm{N}}(\mathrm{t})+\lambda \mathrm{P}_{(\mathrm{N}-1)}(\mathrm{t})
$$

Taking, Laplace Transform of equations (3.1) to (3.4) w.r.t. 't', we have

$$
\mathrm{sP}_{0}^{*}(\mathrm{~s})=1-\lambda \mathrm{P}_{0}^{*}(\mathrm{~s})+\mu \mathrm{P}_{1}^{*}(\mathrm{~s})+\xi \sum_{\mathrm{n}=1}^{\mathrm{N}} \sum_{\mathrm{r}=\mathrm{n}}^{\mathrm{N}} \mathrm{c}_{\mathrm{r}} \mathrm{P}_{\mathrm{n}}^{*}(\mathrm{~s})
$$

$$
\begin{aligned}
& \mathrm{sP}_{1}^{*}(\mathrm{~s})=-(\lambda+\mu+\xi) \mathrm{P}_{1}^{*}(\mathrm{~s})+\lambda \mathrm{P}_{0}^{*}(\mathrm{~s}) \\
& +2 \mu \mathrm{P}_{2}^{*}(\mathrm{~s})+\xi \sum_{\mathrm{r}=1}^{\mathrm{N}-1} \mathrm{c}_{\mathrm{r}} \mathrm{P}_{(1+\mathrm{r})}^{*}(\mathrm{~s}) \\
& \mathrm{sP}_{\mathrm{n}}^{*}(\mathrm{~s})=-(\lambda+2 \mu+\xi) \mathrm{P}_{\mathrm{n}}^{*}(\mathrm{~s})+\lambda \mathrm{P}_{(\mathrm{n}-1)}^{*}(\mathrm{~s})+ \\
& 2 \mu \mathrm{P}_{(\mathrm{n}+1)}^{*}(\mathrm{~s})+\xi \sum_{\mathrm{r}=1}^{\mathrm{N}-\mathrm{n}} \mathrm{c}_{\mathrm{r}} \mathrm{P}_{(\mathrm{n}+r)}^{*}(\mathrm{~s}) \\
& \mathrm{sP}_{\mathrm{N}}^{*}(\mathrm{~s})=-(2 \mu+\xi) \mathrm{P}_{\mathrm{N}}^{*}(\mathrm{~s})+\lambda \mathrm{P}_{(\mathrm{N}-1)}^{*}(\mathrm{~s})
\end{aligned}
$$

Where

$$
\mathrm{P}_{\mathrm{n}}^{*}(\mathrm{~s})=\int_{0}^{\infty} \mathrm{e}^{-\mathrm{st}} \mathrm{P}_{\mathrm{n}}(\mathrm{t}) \mathrm{dt} \text { and }
$$

$P_{n}(0)= \begin{cases}1 & \text { if } n=0 \\ 0 & \text { otherwise }\end{cases}$

Solving this set of equations recursively, we have

$P_{n}^{*}(s)=\rho^{-N}\left\{\rho^{n}+\left[\sum_{i=1}^{\left[\frac{-3+\sqrt{9+8(N-n)}}{2}\right]}\left[\frac{2(N-n)-(i(i-1))}{4} \sum_{1_{0}=i}^{4} \prod_{j=1}^{i-1}\left(\sum_{1_{j}=(i-j)}^{1_{j-1}-1} \prod_{m=0}^{i-1}\left(\sum_{k_{(m+1)}=k_{m}+1}^{\left.A_{m}\right]}\right) \eta \rho^{L_{i}+n} D_{i}\right\} P_{N}^{*}(s)\right.\right.\right.$

$$
\mathrm{n}=2,3, \ldots \ldots ., \mathrm{N}-1
$$




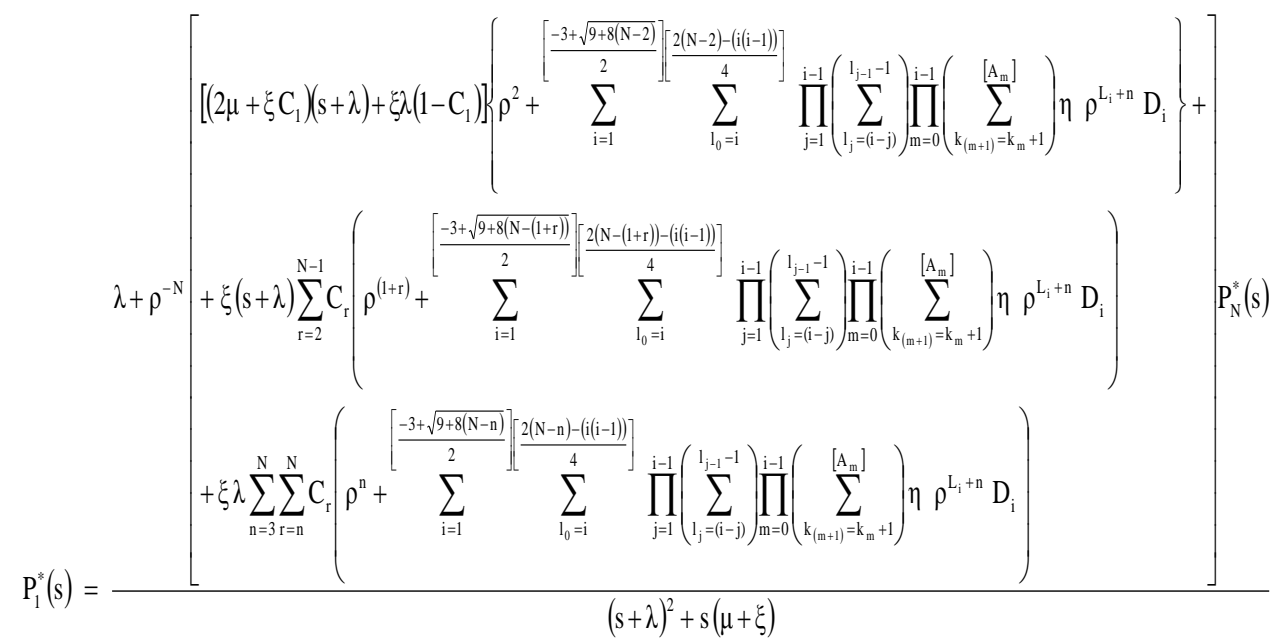

$(s+\lambda)^{2}+s(\mu+\xi)+\lambda(\mu+\xi)+$

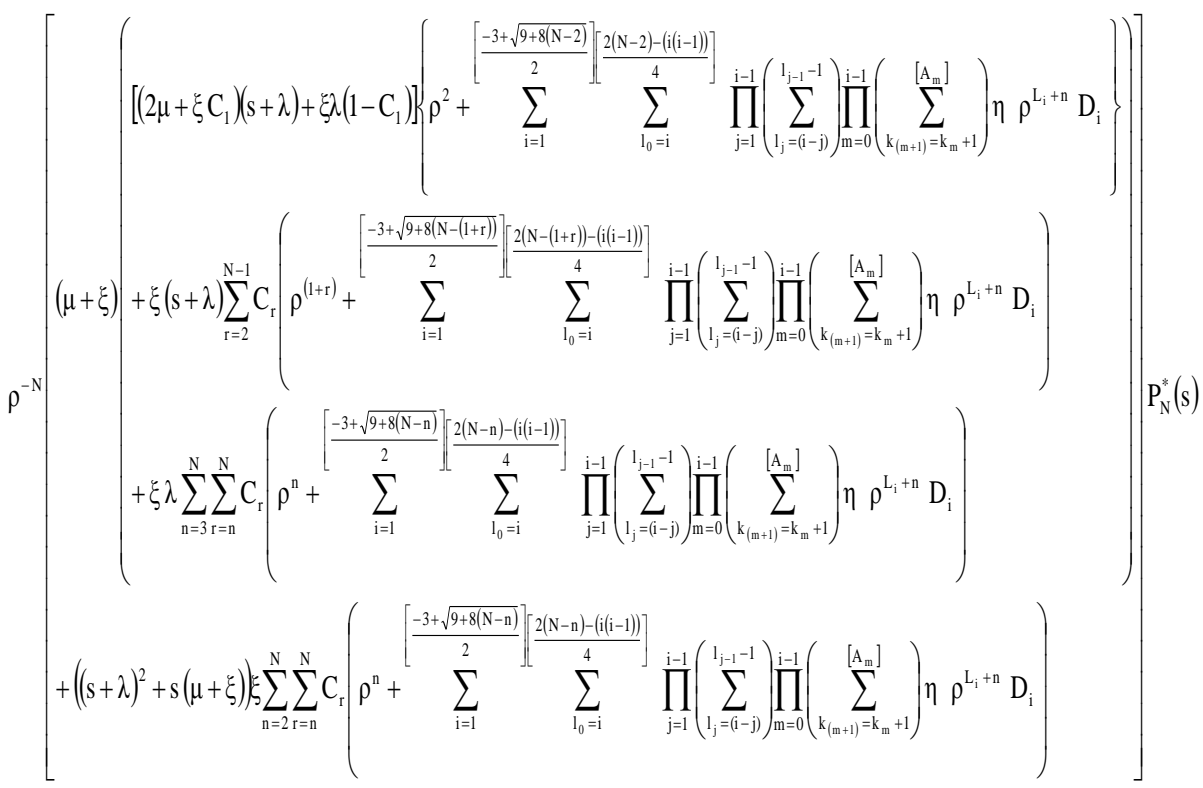

(3.11)

Where

$\rho=\left(\frac{\lambda}{s+2 \mu+\xi}\right)$

$\eta=\prod_{j=1}^{i}\left(\frac{s+\xi\left(1-\sum_{r_{j}=1}^{k_{j}} C_{r_{j}}\right)}{s+2 \mu+\xi}\right)^{I_{(i-j)-1(i-(j-1))}}$

[k] $\rightarrow$ An integral function.

$\prod_{\mathrm{j}}^{\mathrm{i}}=1$ and $\sum_{\mathrm{j}}^{\mathrm{i}}=0$ for $\mathrm{i}<\mathrm{j}, \mathrm{k}_{0}=0$, 


$$
\begin{aligned}
& A_{m}=\frac{N-n-(i-m) l_{0}+\sum_{a=1}^{i-m-1} 1_{a}-k_{m} l_{(i-m)}-\sum_{b=1}^{m-1}\left(k_{(m-b)}-k_{(m-(b-1))}\right) l_{(i+b-m)}}{1_{0}-1_{(i-m)}} \\
& L_{i}=\sum_{j=1}^{i}\left(l_{(i-j)}-1_{(i-(j-1))}\right) k_{j}, \quad 1_{j}= \begin{cases}0 & \text { if } j=i \\
1_{j} & \text { if } 1 \leq j<i\end{cases} \\
& \text { and } \quad D_{i}=\prod_{j=1}^{i}\left(\begin{array}{c}
N-n-L_{i}-1_{(i-(j-1))} \\
l_{(i-j)}-l_{(i-(j-1))}
\end{array}\right)
\end{aligned}
$$

Using normalization condition we have

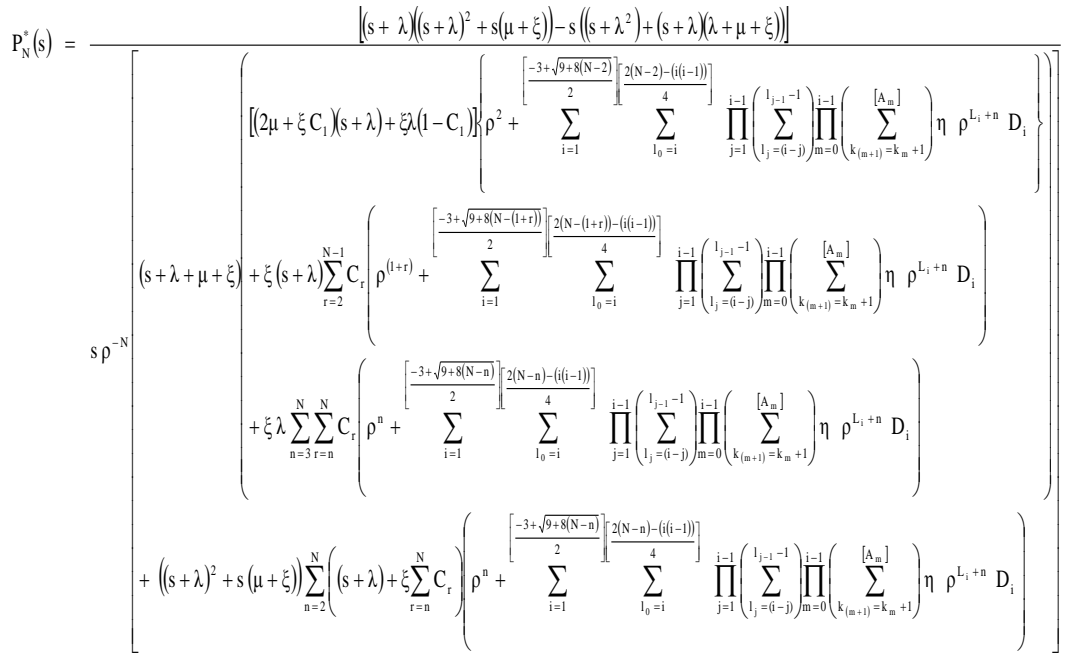

Using (3.12) in(3.9), (3.10) and (3.11), we hav 
$P_{1}^{*}(s)=\frac{\lambda}{(s+\lambda)^{2}+s(\mu+\xi)}+$

$a\left[(s+\lambda)\left((s+\lambda)^{2}+s(\mu+\xi)\right)-s\left(\left(s+\lambda^{2}\right)+(s+\lambda)(\lambda+\mu+\xi)\right)\right]$

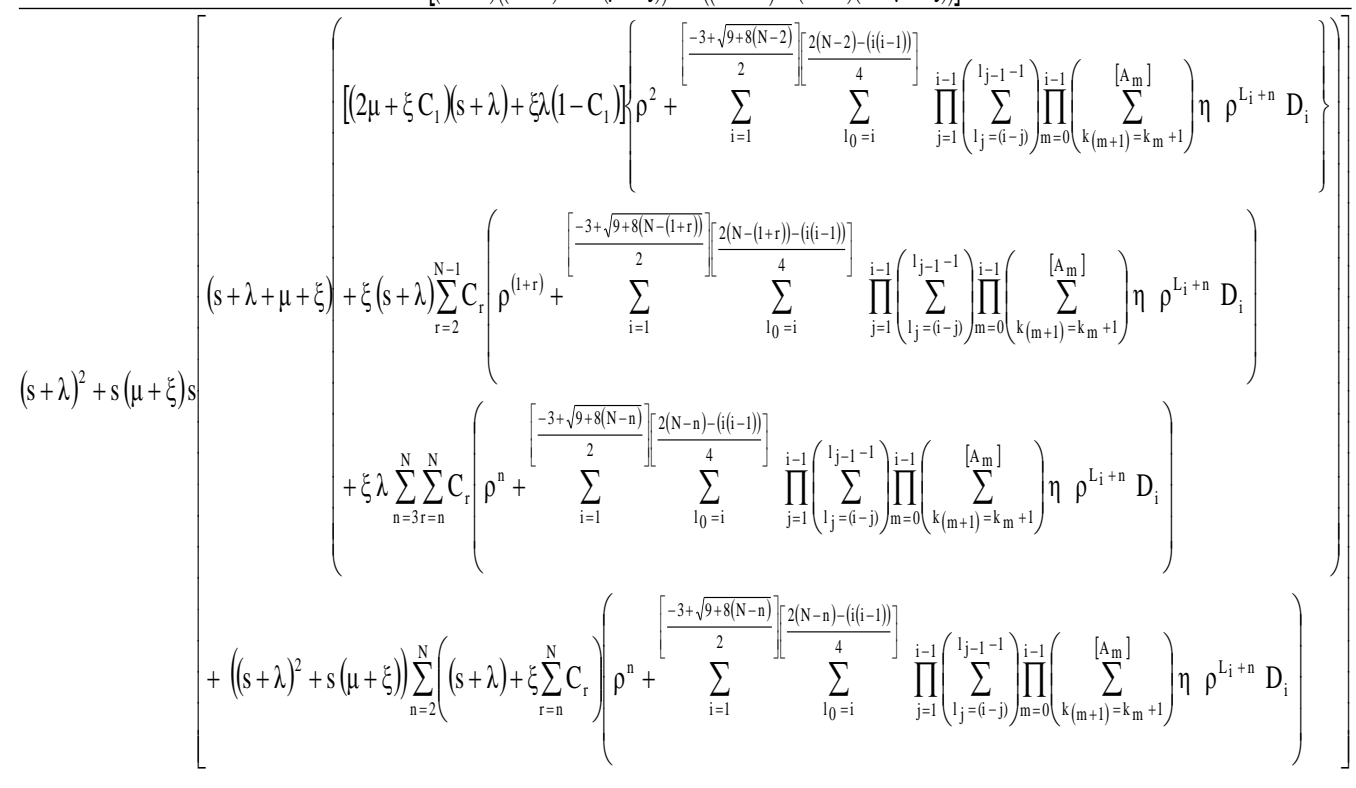

$\mathrm{P}_{0}^{*}(\mathrm{~s})=\frac{\left(\mathrm{F}_{1}+\lambda(\mu+\xi)\right)}{\mathrm{F}_{1}}+$

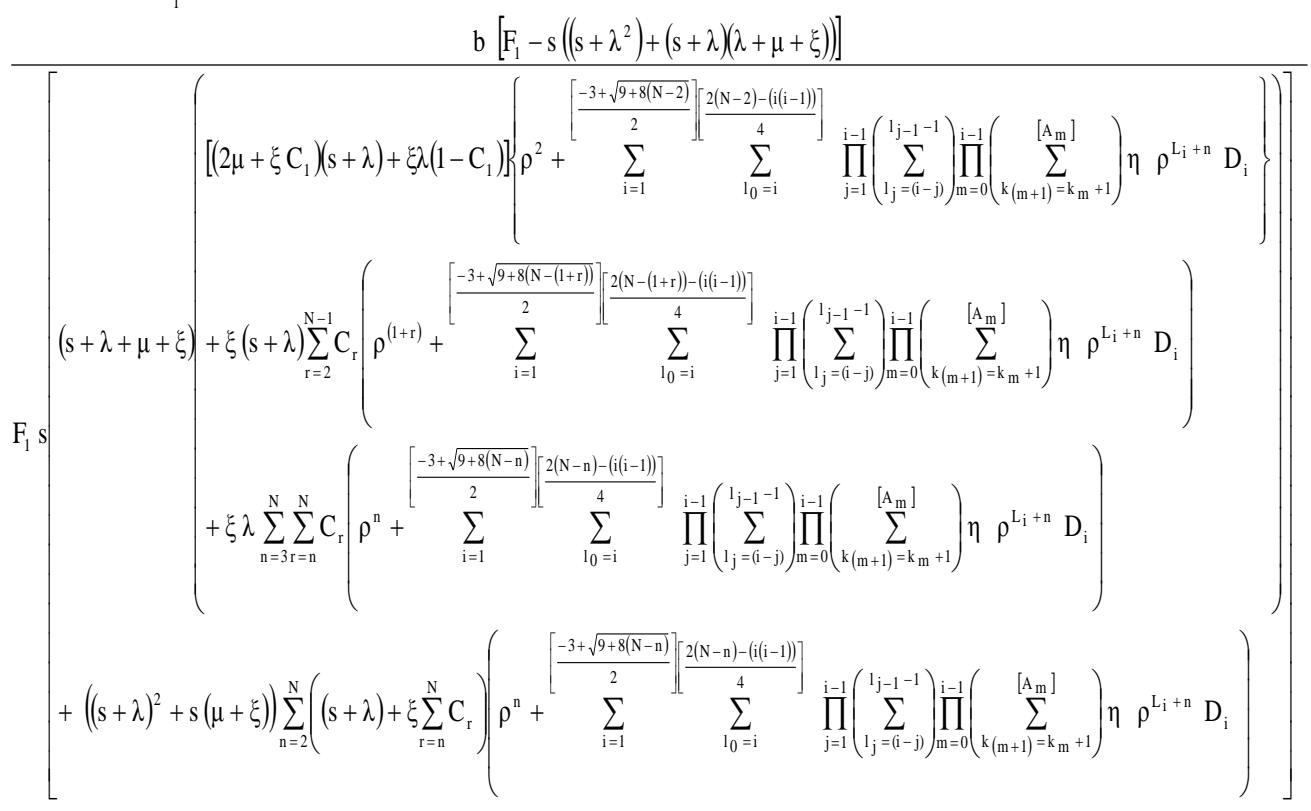

Where 


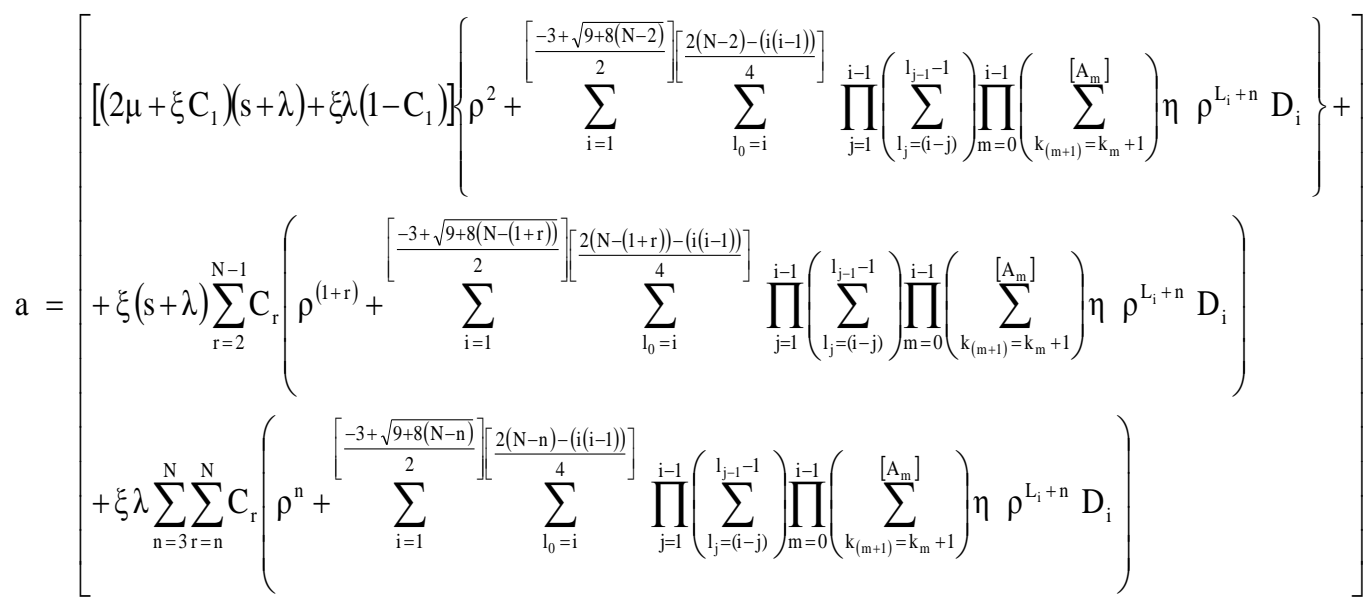

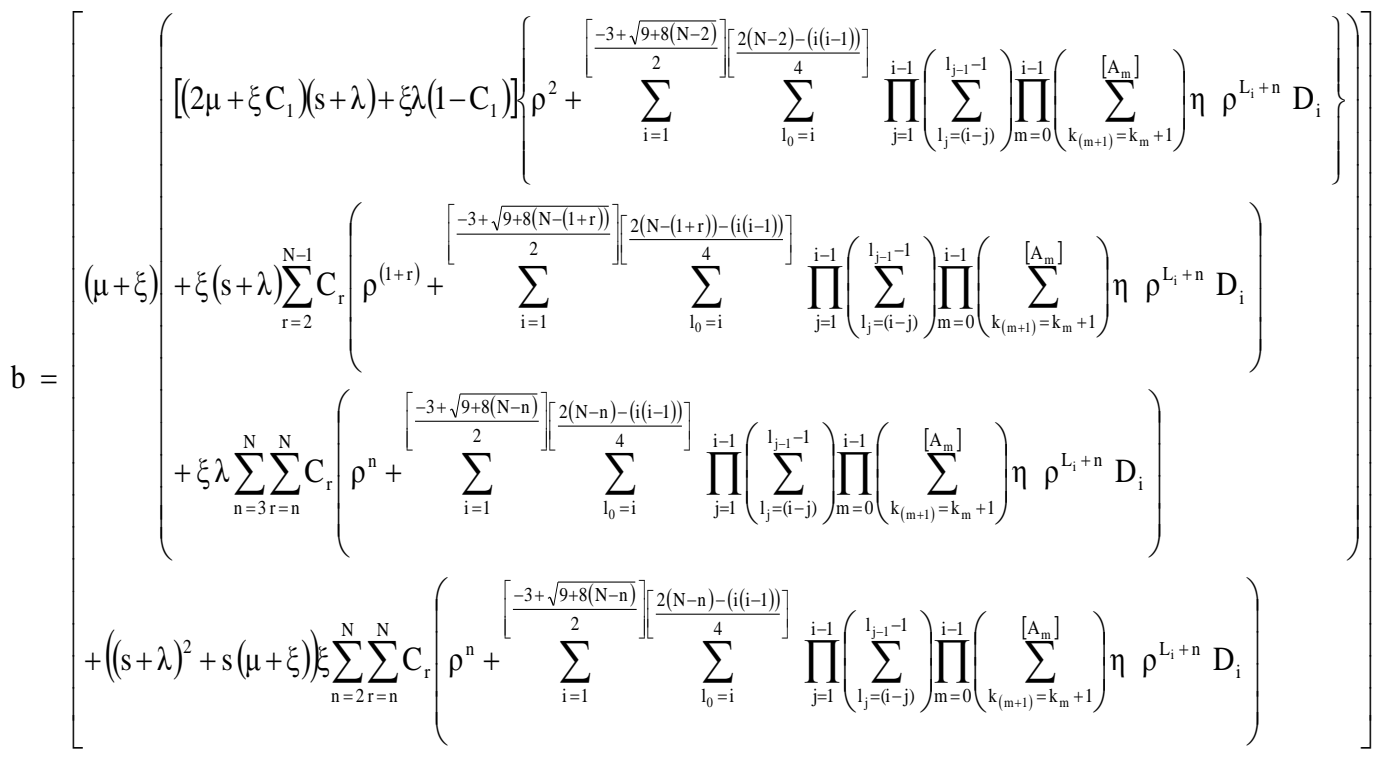

$$
\begin{aligned}
& \mathrm{F}_{1}=\left[(\mathrm{s}+\lambda)\left((\mathrm{s}+\lambda)^{2}+\mathrm{s}(\mu+\xi)\right)\right\rfloor
\end{aligned}
$$

After taking the Laplace inverse of (3.13), (3.14) and (3.15) we can find all the probabilities.

\section{STEADY STATE SOLUTION}

Using the property

$\lim _{s \rightarrow 0} s P_{n}^{*}(s)=P_{n}$, We have from (3.13), (3.14) and (3.15) 


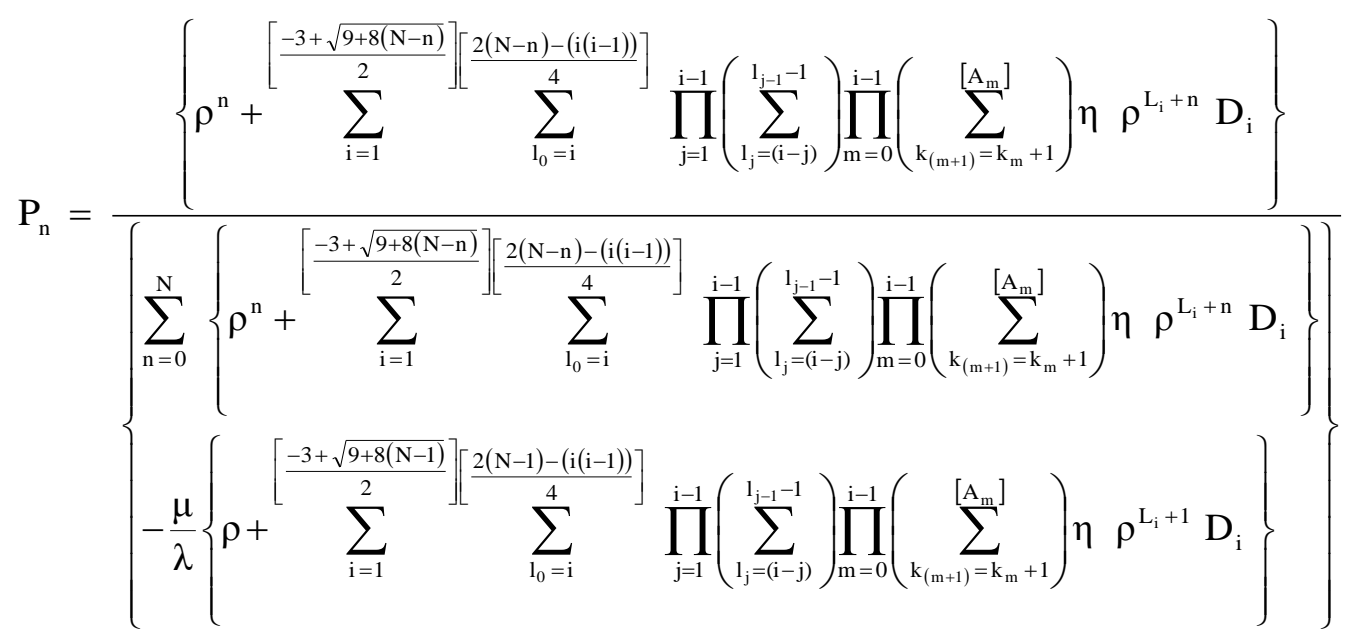

And

$$
\mathrm{n}=1,2,3 \ldots, \mathrm{N}
$$

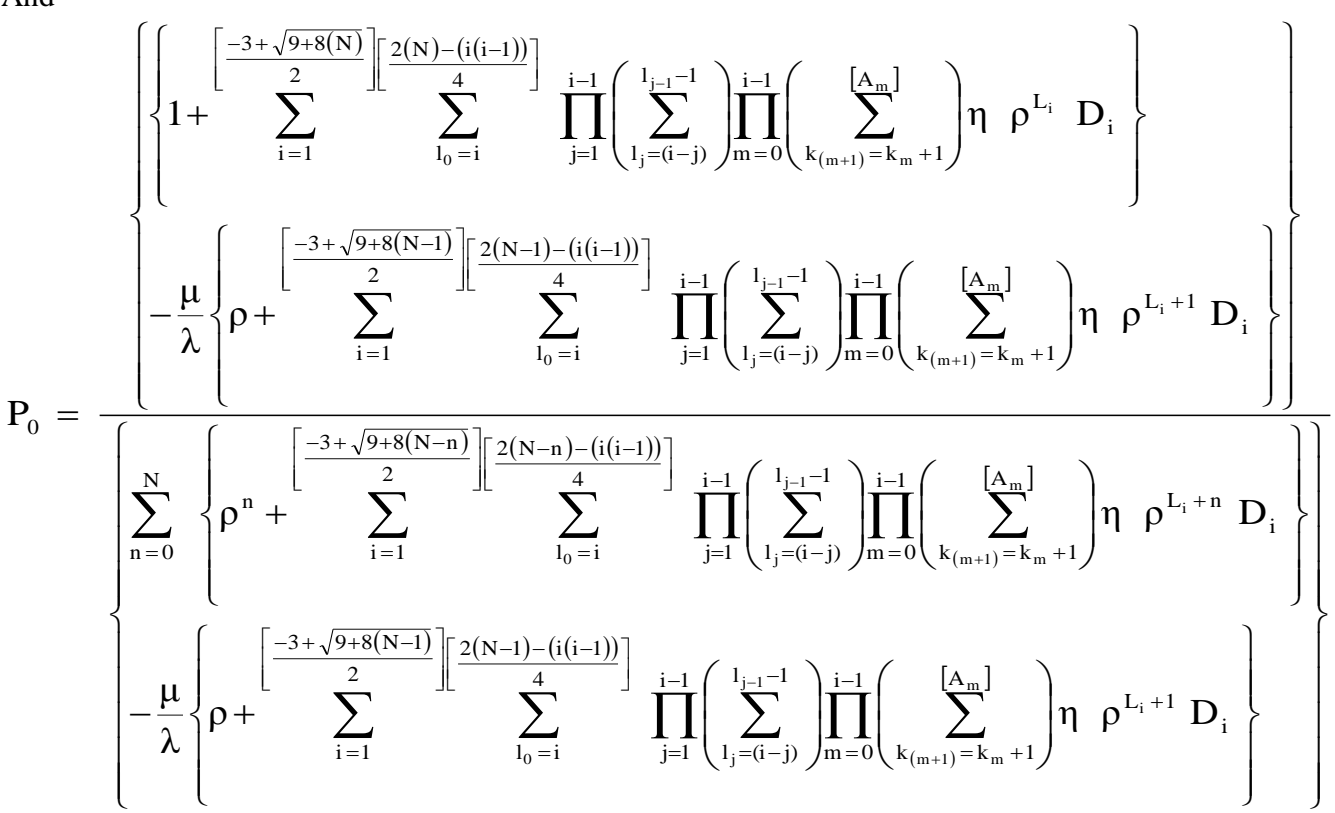

\section{MEASURE OF EFFECTIVENESS}

The steady state probability distribution for the system size allows us to calculate what are commonly called measures of effectiveness. Two, of immediate interest are the expected number of customers in the system and the expected number of customers in the queue.To derives the foregoing measures, let $\mathrm{L}_{\mathrm{s}}$ represents the expected number in the system and $\mathrm{L}_{\mathrm{q}}$ represents the expected number in the queue. Thus we have 


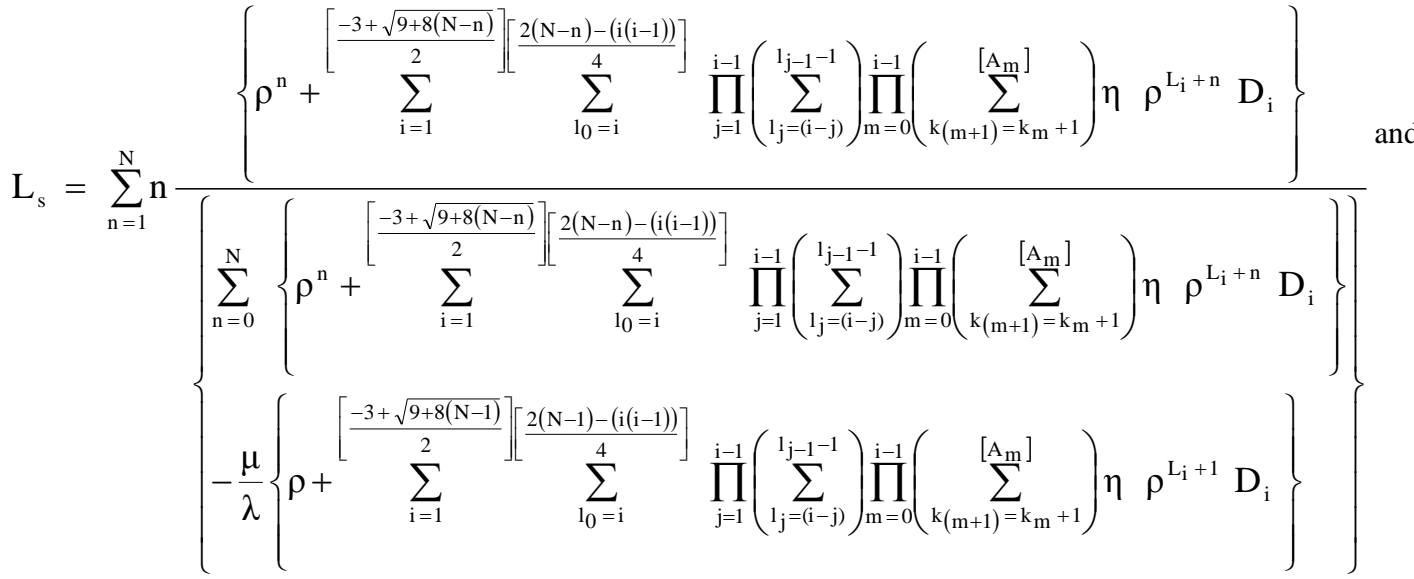

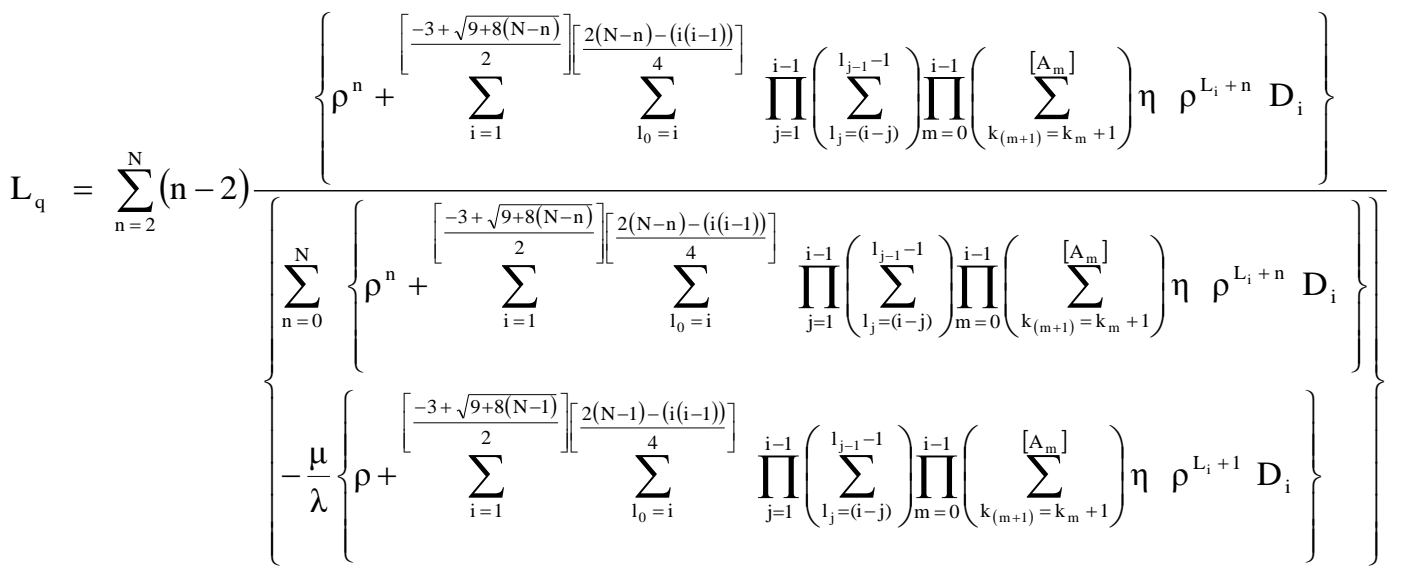

\section{IMPORTANT PARTICULAR CASE OF THE MODEL}

In case the catastrophic intensity follows the uniform distribution then we get:

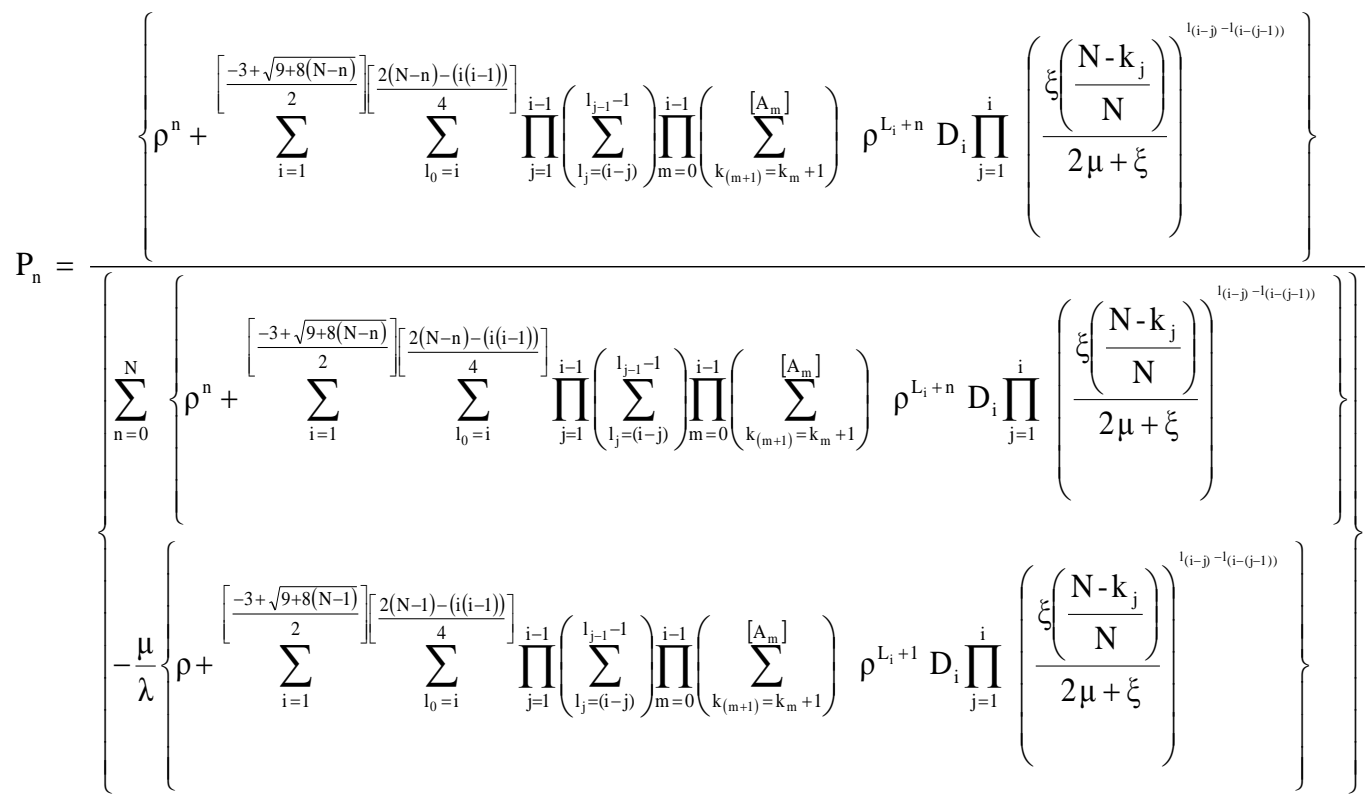




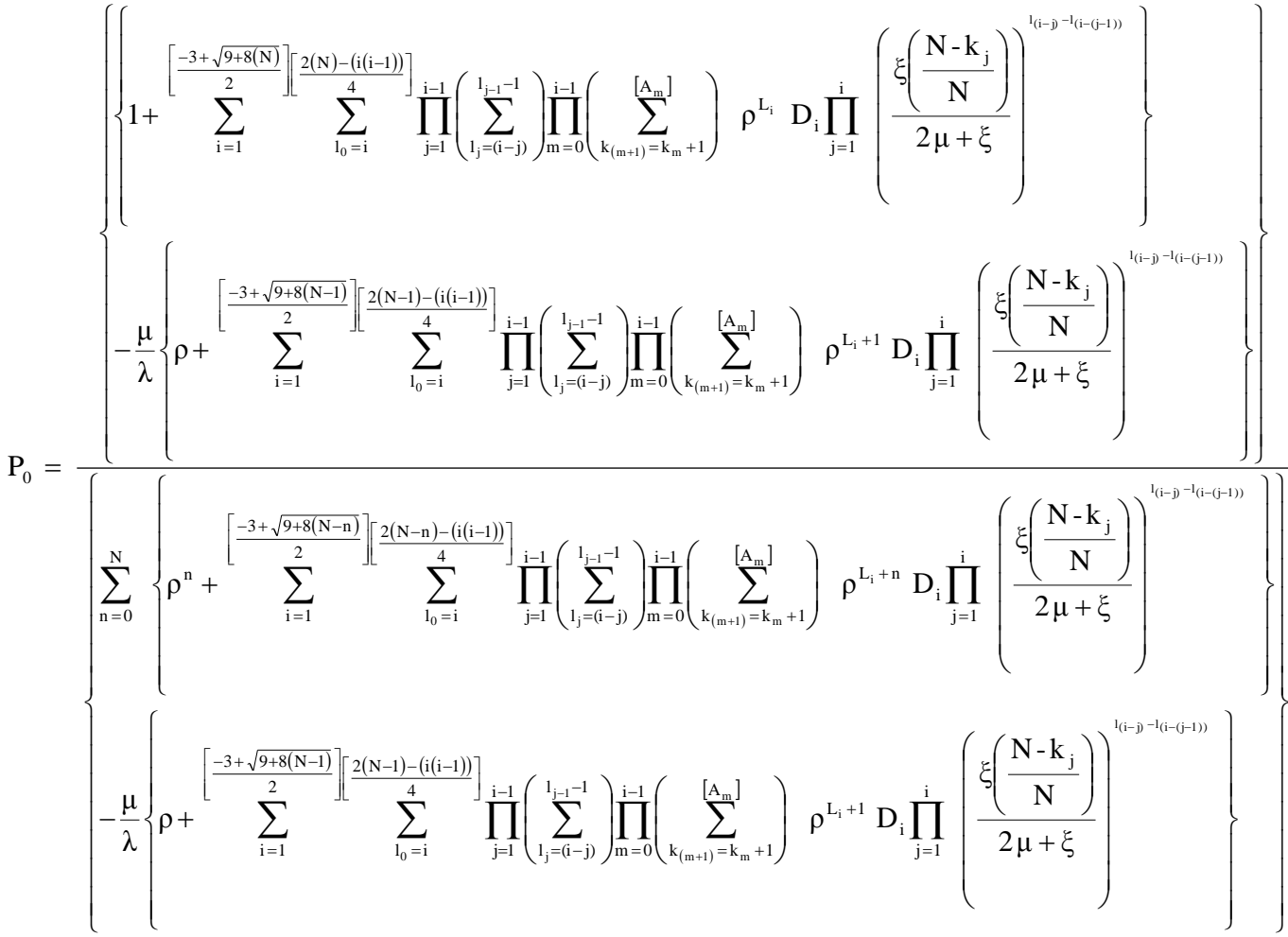

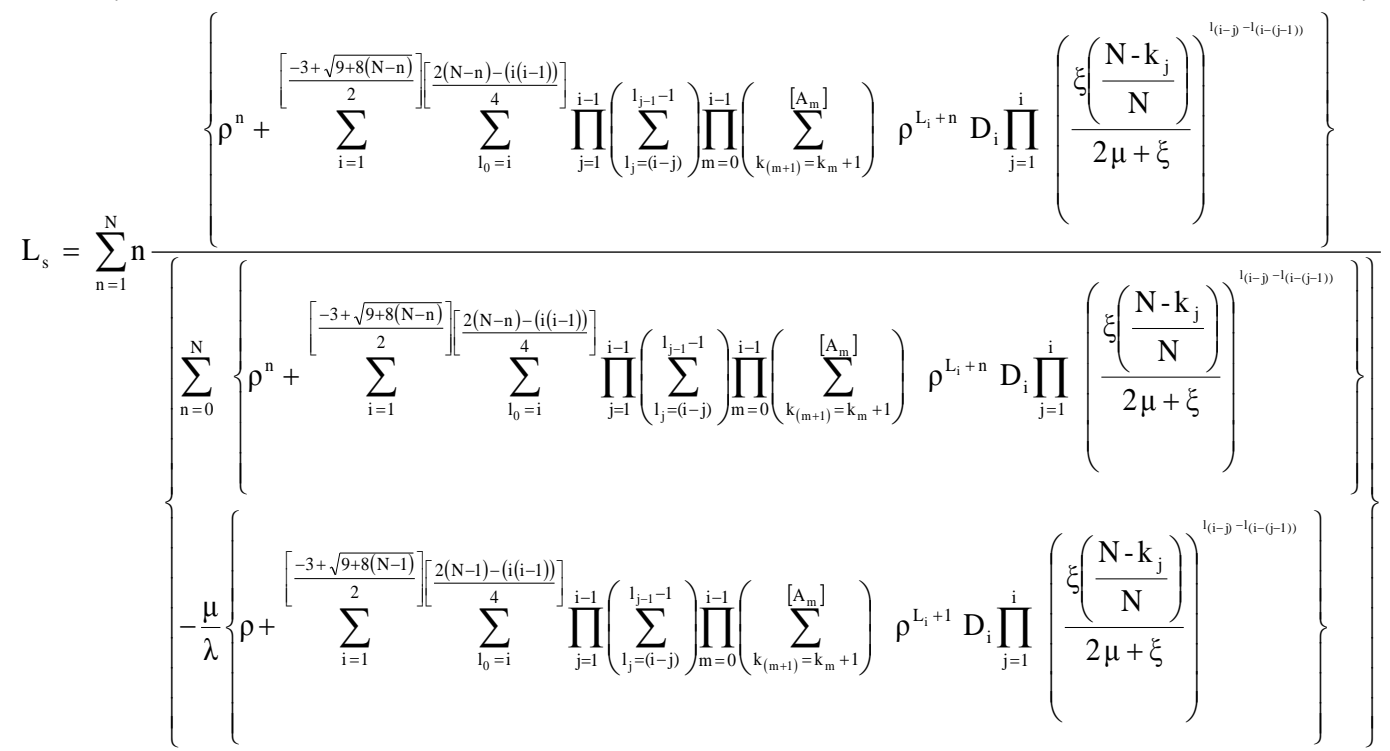




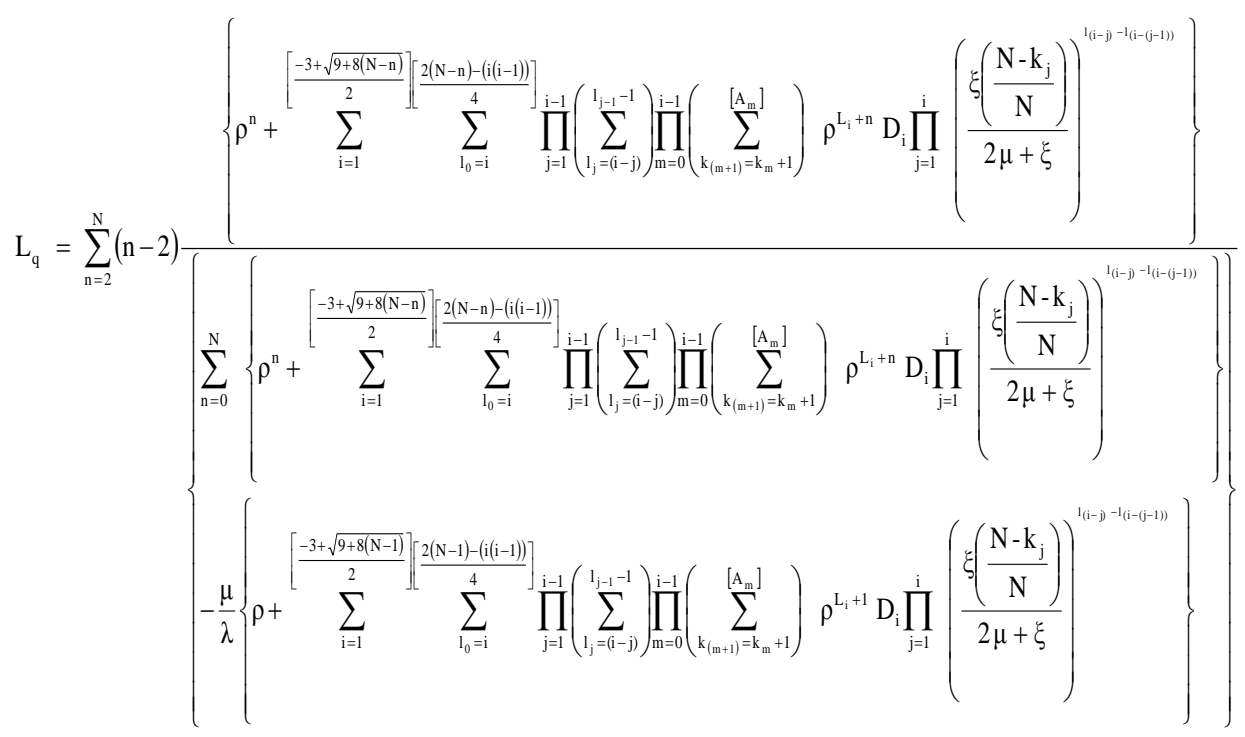

\section{CONCLUSION}

In this paper we consider a two homogeneous server markovian queueing system subjected to varying catastrophic intensity. The system size probabilities are calculated explicitly. The concept of varying catastrophic intensity is very important from practical point of view in a

\section{REFERENCES}

[1] Bartoszynski, R. Buhler, W.J., Chan, W., and Pearl, D.K. (1989), Population processes under the influence of disasters occurring independently of population size, J. Math. Bio. Vol, 27, 179-190.

[2] Brockwell, P.J., Gani, J.M. and Resnick, S.I. (1982), Birth immigration and catastrophe processes, Adv. Applied Probability,Vol. 14, 709-731.

[3] Brockwell, P.J. (1985), The extinction time of a birth, death and catastrophe process and of a related diffusion model, Advances in Applied Probability,Vol. 17, 42-52.

[4] Chao, X. (1995), A queueing network model with catastrophes and product form solution, Operations Research Letters, Vol. 18, 75-79.

[5] Chao, X. and Zheng, Y. (2003), Transient analysis of immigration birth- death processes with total catastrophes, Prob. Enggn. and Inform. Sciences, Vol. 17, 83-106.

[6] Crescenzo, A. Di, Giorno, V., Nobile, A. G. and Ricciardi, L.M. (2003), On the M/M/1 queue with catastrophes and its continuous approximation, Queueing Systems, Vol. 43, 329-347.

[7] Jain, N.K. and Kanethia, D.K. (2006), Transient analysis of a queue with environmental and Catastrophic effects, International Journal of Information and Management Sciences, Vol. 17, No.1.35-45.

[8] Jain, N.K. and Kumar Rakesh, (2007), Transient solution of a catastrophic-cum-restorative queuing problem with correlated arrivals and variable service capacity, Int. J. of Inform. And Manag. Sci., Taiwan, Vol. 18, 461-465 vide variety of areas such as computer communication, agriculture and biosciences etc.

\section{ACKNOWLEDGEMENT}

The author thanks the anonymous referees for their valuable comments and suggestion to improve the presentation of the paper.

[9] Jain, N.K. and Bura Gulab Singh, (2010), A queue with varying catastrophic intensity, International journal of computational and applied mathematics, Vol. 5, 41-46.

[10] Kitamura, K., Tokunaga, M., Hikkikoshi, A. and Yanagida, T. (1999), A single myosin head move along an actin filament with regular steps of 5.3 nanometers, Nature, Vol. 397, 129-134.

[11] Kumar, B.K. and Arivudainambi, D. (2000), Transient solution of an $\mathrm{M} / \mathrm{M} / 1$ queue with catastrophes, Comp. and Mathematics with Applications, Vol. 40, 1233-1240.

[12] Kumar, B.K. and Madheswari, Pavai S., (2002), Transient behavior of the $\mathrm{M} / \mathrm{M} / 2$ queue with catastrophes, Statistica, Vol. 27, 129-136.

[13] Kumar, B.K., Madheswari, Pavai S. and Venkatakrishnan, K.S., (2007), Transient solution of an $\mathrm{M} / \mathrm{M} / 2$ queue with heterogeneous servers subject to catastrophes, International Journal of Information and Management Sciences, Vol. 18, 63-80.

[14] Kyriakidis, E.G. (1994), Stationary probabilities for a simple immigration-birth-death process under the influence of total catastrophes, Stat. and Prob. Letters, Vol. 20, 239-240.

[15] Kyriakidis, E.G. (2001), The transient probabilities of the simple immigration- catastrophe process, Math.Scientist, Vol. 26, 56--58.

[16] Miyazaki, Y. and Sibata, S. Mori, (1992), Transient behavior of the $\mathrm{M} / \mathrm{M} / 2 / \infty / \mathrm{FIFO}$ queue with starting customers, Journal of information and optimization sciences, Vol. 13, 1-27. 
[17] Rubinovitch, M.,(1985), The slow server problem, Journal of applied probability, Vol. 22, 205-213.

[18] Saaty, T.L. (1960), Time dependent solution of the many server Poisson queue, Operations Research, Vol. 8, 755-772.
[19] Singh, V.P.,(1970), Two servers Markovian queues with balking: Heterogeneous vs. homogeneous servers, Operations Research, Vol. 19, 145-159. 